\title{
ANALISIS PENERAPAN MANAJEMEN PERSEDIAAN BAHAN BAKU PADA USAHA SARI TAHU GUNUNG KANCIL KABUPATEN PRINGSEWU TAHUN 2019
}

\author{
Wagiyo', Ikke Sinta Bella ${ }^{2}$, Dhel Juni Pasya ${ }^{3}$ \\ ${ }^{1,2}$ Fakultas Ekonomi dan Bisnis Universitas Muhammadiyah Pringsewu \\ Email : wagiyo61@yahoo.com; ikkesintabella27@gmail.com, dheljunifeb@umpri.ac.id
}

\section{ABSTRAK}

Persediaan merupakan sumber daya yang dimiliki perusahaan, berupa barang-barang yang akan digunakan untuk keperluan dimasa yang akan datang. Persediaan meliputi barang dagang milik perusahaan yang dapat dijual kembali atau digunakan dalam proses produksi, persediaan dapat berbentuk bahan baku, barang setengah jadi dan barang jadi yang siap untuk dijual.

Masalah dalam penelitian ini adalah Usaha Sari Tahu belum menerapkan manajemen persediaan bahan baku. Adapun rumusan masalah dalam penelitian ini adalah bagaimana penerapan maajemen persediaan bahan baku dengan metode Economic Order Quantity (EOQ) pada Usaha Sari Tahu Gunung Kancil Kabupaten Pringsewu Tahun 2019?. Tujuan Penelitian ini Ingin mengetahui Penerapan manajemen Persediaan Bahan Baku dengan Metode EOQ Pada Usaha Sari Tahu Gunung Kancil Kabupaten Pringsewu Tahun 2019.

Analisis data yang digunakan pada penelitian ini adalah Economic Order Quantity (EOQ), Frekuensi Pembelian, Persediaan Bahan Pengaman (Safety Srock), Pemesanan Kembali (Reorder Poin), dan Total Biaya Persediaan atau Total Investory Cost (TIC). Berdasarkan analisis data yang sudah dilakukan, maka diperoleh hasil bahwa pembelian bahan baku yang dilakukan Usaha Sari Tahu Gunung Kancil Pringsewu cenderung tidak efisisen karena biaya total persediaan menggunakan kebijakan perusahaan lebih besar dibandingkan dengan menggunakan metode Economic Order Quantity (EOQ). Hasil penelitian menunjukan bahwa dengan metode Economic Order Quantity (EOQ) persediaan bahan baku yang optimal di Usaha Sari Tahu Gunung Kancil Pringsewu Tahun 2017 yaitu 2.066,69 kg Frekuensi pembelian sebanyak 14 kali 890,6 kg Persediaan Pengaman 1.087,5 kg Pemesanan Kembali 1.343.349,75 Total Investory Cost dan pada tahun 2018 2.105,60 kg Frekuensi pembelian 15 kai 803,07 kg Persediaan Pengaman 1.009,97 kg Pemesanan Kembali dan 1.473.923 Total Investory Cost.

Kata Kunci: Persediaan, Economic Order Quantity.

\section{PENDAHULUAN}

Manajemen yang baik memiliki fungsi yang sangat penting dalam perusahaan untuk mengontrol kegiatan supaya berjalan dengan lancar dan efektif. Perusahaan juga harus mampu meningkatkan kinerja, khususnya dalam proses produksi sehingga menghasilkan produk yang berkualitas dan memenuhi harapan konsumen.

Supaya perusahaan mampu mencapai laba yang optimal yaitu salah satunya suatu kebijakan manajemen dengan memperhitungkan persediaan yang optimal, dengan menyeimbangkan kebutuhan bahan baku yang tidak terlalau banyak maupun persediaan yang tidak terlalu sedikit.

Persediaan bahan baku haruslah dilakukan sebaik-baiknya dengan mempertahankan waktu pemesanan maka biaya- biaya yang seharusnya tidak dikeluarkan dapat ditekan. Persediaan bahan baku yang terlalu banyak bila dilihat dari proses produksi maka tidak akan mengalami gangguan karena persediaan bahan baku selalu ada. Namun disisi lain persediaan bahan baku yang terlalu banyak akan menimbulkan resiko tinggi biaya penyimpanan, 
resiko kehilangan dan kerusakan bahan baku semakin besar. Sebaliknya, bila persediaan bahan baku terlalu sedikit menimbulkan resiko terjadinya kekurangan persediaan (stock-out) karena seringkali barang tidak dapat didatangkan secara mendadak dan sebesar dibutuhkan, yang menyebabkan terhentinya proses produksi, tertundaya keuntungan, hilangnya pelanggan. Jumlah persediaan yang dibutuhkan tergantung dari volume produksi, jenis pabrik dan proses.

Supaya perusaahaan dapat beroprasi lebih efisien maka aktivitas pembeliaan bahan baku perlu direncanakan dengan menggunakan metode yang tepat. Yaitu metode pengadaan persediaan analisis ABC dan Economic Order Quantity (EOQ) . EOQ ialah jumlah pesanan dalam periode tertentu harus sedemikian rupa sehingga jumlah biaya pemesanan dan biaya penyimpanan harus sama besarnya.

Berdasarkan pra penelitian penulis, Sari Tahu Gunung Kancil merupakan industri rumah tangga yang usaha yang memproduksi pembuatan tahu. Bahan baku utama yang digunakan dalam proses produksi ini adalah Kedelai. Dalam kegiatan perusahaan membuat kebijakan mengenai pengelolaan persediaan bahan baku dengan cara konvensional yaitu melakukan pembelian secara terus menerus dengan memperkirakan kebutuhan produksi dan belum menerapkan manajemen persediaan bahan baku. Berikut ini adalah data pembelian dan pemakaian bahan baku Kedelai pada produksi Tahu Gunung Kancil Pringsewu dapat dilihat pada tabel 1 dibawah ini .

Tabel 1

Persediaan Bahan Baku Kedelai Tahun 2017/ 2018 (dalam satuan $\mathrm{Kg}$ )

\begin{tabular}{|c|l|c|c|c|c|}
\hline \multirow{2}{*}{ No } & \multirow{2}{*}{ Bulan } & \multicolumn{2}{|c|}{ Tahun 2017} & \multicolumn{2}{c|}{ Tahun 2018} \\
\cline { 3 - 6 } & & $\begin{array}{c}\text { Kebutuhan } \\
\text { bahanbaku }\end{array}$ & $\begin{array}{c}\text { Pembelian } \\
\text { bahan baku }\end{array}$ & $\begin{array}{l}\text { Kebutuhan } \\
\text { bahanbaku }\end{array}$ & $\begin{array}{c}\text { Pembelian } \\
\text { bahanbaku }\end{array}$ \\
\hline 1. & Januari & 2295 & 2500 & 2570 & 2700 \\
\hline 2. & Febuari & 2040 & 2500 & 2400 & 2500 \\
\hline 3. & Maret & 2430 & 2500 & 2430 & 2500 \\
\hline 4. & April & 2340 & 2500 & 2340 & 2500 \\
\hline 5. & Mei & 2565 & 3000 & 2700 & 3000 \\
\hline 6. & Juni & 2600 & 3000 & 2800 & 3000 \\
\hline 7. & Juli & 2800 & 3000 & 4050 & 4500 \\
\hline 8. & Agustus & 4050 & 4500 & 2700 & 3000 \\
\hline 9. & September & 2080 & 2500 & 2080 & 2500 \\
\hline 10. & Oktober & 2360 & 2500 & 2460 & 2500 \\
\hline 11. & November & 1950 & 2000 & 2210 & 2500 \\
\hline 12. & Desember & 2025 & 2500 & 2295 & 2500 \\
\hline Jumlah & 29535 & 33000 & 31035 & 33700 \\
\hline Rata - rata & 2461,25 & 2750 & 2586,25 & 2808,33 \\
\hline
\end{tabular}

Sumber : Data persediaan bahan baku kedelai usaha Sari Tahu Gunung Kancil Pringsewu tahun 2017-2018

\section{KAJIAN PUSTAKA}

\section{A. Persediaan}

\section{Pengertian Persediaan}

Persediaan merupakan salah satu komponen penting bagi kelangsungan perusahaan karena persediaan dapat menunjukan segala sesuatu atau sumber daya organisasi yang disimpan dalam antisipasinya terhadap pemenuhan permintaan. . Persediaan merupakan asset atau aktiva lancar yang dimiliki perusahaan yang biasanya melakukan kegiatan bisnis dengan menjual barang dagangan atau barang hasil produksinya. Sehingga perusahaan harus memiliki kemampuan dalam mengatur dan mengelola setiap kebutuhan bahan baku agar selalu tersedia baik dalam kondisi pasar yang stabil dan fluktuasi.

Menurut Anantasia Diana Lilis Setiawati (2017: 191) metode yang digunakan untuk melakukan pencatatan jumlah persediaan yaitu :

a. Metode Waighted Average (Rata-rata Tertimbang) yaitu metode persediaan dimana biaya setiap unit ditentukan berdasarkan biaya rata-rata tertimbang dari unit yang serupa dari awal periode dan biaya unit yang serupa yang dibeli atau diproduksi selama satu periode.

b. Metode FIFO (First-in, First-out) yaitu metode persediaan yang mengasumsikan unit persediaan yang pertama dibeli akan dijual (digunakan) terlebih dahulu, sehingga unit yang tertinggal dalam persediaan akhir adalah yang dibeli (diproduksi) kemudian.

c. Metode LIFO (Lasti-in, First-out) yaitu metode penilaian persediaan yang terakhir masuk diasumsikan akan keluar atau dijual pertama kali. Metode ini memiliki konsep yang cukup sederhana namun sulit dilaksanakan. Pengaruh penggunaan metode LIFO terhadap penentuan laba bersih usaha, jika harga cenderung maik maka laba perusahaan terlalu kecil atau sebaliknya

\section{Tujuan Persediaan}

Tujuan persediaan yaitu kebijakan persediaan untuk merencanakan tingkat optimal investasi persediaan dan mempertahankan tingkat optimal 
tersebut melalui persediaan. Karena tujuan persediaan agar permintaan konsumen dapat dipenuhi serta produksi perusahaan dapat berjalan secara efektif dan efisien.

Menurut Sri Suharti (2018: 64) tujuan persediaan secara terinci dinyatakan sebagai usaha untuk :

a. Menghilagkan resiko keterlambatan datangnya barang atau barang-barang yang dibutuhkan perusahaan.

b. Menjamin kelancaran proses produksi perusahaan.

c. Dapat melaksanakan produksi sesuai keinginan tanpa menunggu adanya dampa atau resiko penjualan.

Sehingga dapat dimengerti bahwa tujuan persediaan untuk memperoleh kualitas dan jumlah yang tepat dari bahan- bahan yang tersedia pada waktu yang dibutuhkan.

\section{Fungsi Persediaan}

Fungsi persedian yaitu sebagai penyangga, penghubung antar proses produksi dan distribusi untuk memperoleh efisiensi. Dan berguna untuk memenuhi fluktuasi permintaan yang tidak dapat dengan segera dipenuhi oleh produksi mengingat untuk produksi dibutuhkan bahan baku.

\section{Jenis-Jenis Persediaan}

Jenis - jenis persediaan mempunyai karakteristik khusus dan cara pengelolaannya juga berbeda. Persediaan bisa berupa bahan mentah, bahan pembantu, bahan dalam proses, dan barang jadi atau suku cadang. Karna dalam jenis-jenis persediaan dibutuhkan untuk perusahaan dalam menjalankan usahanya.

Menurut Heizer dan Render (2016: 554) perusahaan memiliki 4 jenis persediaan, yaitu:

1) Persediaan bahan mentah (raw material inventory) Telah dibeli, tetapi belum diproses. Persediaan ini dapat digunakan untuk memisahkan (yaitu, menyaring) pemasok dari proses produksi.

2) Persediaan barang dalam proses (work-inprocess-WIP inventory) Komponen-komponen atau bahan mentah yang telah melewati beberapa proses perubahan, tetapi belum selesai.

3) M.R.O (maintenance / repair / operating) Persediaan yang disediakan untuk perlengkapan pemeliharaan/perbaikan/operasi (maintenance/repair/operating-MRO) yang dibutuhkan untuk menjaga agar mesin dan proses tetap produktif.

4) Persediaan barang jadi (finish-good inventory)Produk yang telah selesai dan tinggal menunggu pengiriman. Barang jadi dapat dimasukkan ke persediaan karena permintaan pelanggan pada masa mendatang tidak diketahui.

\section{Biaya Persediaan}

Biaya persediaan bahan baku merupakan biaya yang timbul karena perusahaan menyimpan persediaan bahan baku tersebut didalam gudang, persediaan bisa menimbulkan biaya yang banyak jumlahnya karena banyak jenisnya yang perlu Membutuhkan biaya persediaan seperti biaya penyimpanan,biaya persiapan, biaya pemesanaan.

Biaya persediaan yang meliputi :

a. Biaya untuk memperoleh barang (ordering cost) melalui pembelian (purchasing) atau mengolah (manufacturing or set up cost). Hal ini merupakan biaya tetap per lot, tetapi biaya variabel per unit atau satuan barang.

b. Biaya penyimpanan satu satuan (unit) barang dalam persediaan (holding cost), yang meliputi antara lain biaya penyimpanan, niaya penyampaian, biaya kerusakan, biaya asuransi, pajak dan lain sebagainya.

c. Biaya kekurangan (cost of shortage) meliputi biaya yang disebabkan karena keterlambatan didalam memenuhi permintaan atau ketidak mampuan untuk memenuhinya sama sekali, karena kehabisan stok misalnya.

\section{Pengendalian Persediaan Bahan Baku}

Pengendalian persediaan merupakan salah satu fungsi manajerial yang sangat penting untuk dilakukan dalam kegiatan produksi karena adanya persediaan fisik yang banyak serta perusahaan melibatkan investasi rupiah terbesar dalam aktiva.

Menurut Irham Fahmi (2016: 109) mengemukakan bahwa: "Pengendalian persediaan adalah kemampuan suatu perusahaan dalam 
mengatur dan mengelola setiap kebutuhan barang baik barang mentah, barang setengah jadi, dan barang jadi agar selalu tersedia baik dalam kondisi pasar yang stabil dan berfluktuasi”. Sedangkan Menurut Johannes Supranto (2013: "untuk pengamanan persediaan harus disediakan apa yang disebut buffer stock, hal ini untuk mencegah terjadinya kekurangan (shortages)".

\section{B. Metode Pengendalian Persediaan Bahan Baku}

\section{Analisis ABC}

a. Pengertian Analisis ABC

Berdasarkan beberapa pendapat para ahli bahwa analisis ABC adalah metode persediaan untuk mengendalikan sejumlah kecil barang,tetapi mempunyai nilai investasi yang tinggi.

\section{b. Kriteria - kriteria Analisis ABC}

Menurut Gatot Nazir Ahmad (2018 :172) terdapat beberapa kriteria dalam klasifikasi $\mathrm{ABC}$ :

1) Kelas $A$ adalah persediaan dengan volume tahunan rupiah yang tinggi. Kelas ini mewakili sekitar $70 \%$ dari total persediaan, meskipun jumlahnya hanya sedikit sekitar $20 \%$ dari seluruh item.

2) Kelas $B$ adalah persediaan dengan nilai volume tahunan rupiah pada tingkat menengah. Kelompok ini mewakili sekitar $20 \%$ dari total nilai persediaan tahunan dan sekitar $30 \%$ dari umlah item.

3) Kelas $\mathrm{C}$ adalah barang dengan nilai volume tahunan rupiah yang rendah sehingga mewakili sekitar $10 \%$ dari total nilai persediaan. Kelas ini terdiri dari sekitar $50 \%$ dari jumlah item persediaan.

\section{Economic Order Quantity ( $E O Q$ )}

\section{a. Pengertian Economic Order Quantity (EOQ)}

Irham Fahmi (2016: 120) mengemukakan "Metode Economic Order Quantity (EOQ) merupakan model matematik yang menentukan jumlah barang yang harus dipesan untuk memenuhi permintaan yang diproyeksikan, dengan biaya persediaan yang diminta".

Heizer dan Render (2016: 562) mengemukakan "Metode kuantitas pesanan ekonomis (Economic Order Quantity - EOQ) adalah salah satu teknik kontrol persediaan yang meminimalkan biaya total dari pemesanan dan penyimpanan". Economic Order
Quantity - EOQ merupakan teknik control persediaan yang tertua dan paling terkenal.

Rumus yang digunakan adalah:

Jumlah biaya penyimpanan selama satu periode sama dengan :

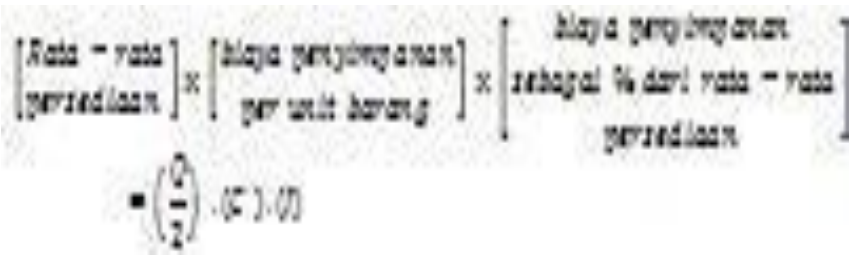

Dalam hal ini C . I = biaya penyimpanan setahun dari 1 satuan (unit) barang.

Jumlah biaya pemesanan sama dengan :

$$
\left[\begin{array}{c}
\text { banyaknya pesanan } \\
\text { per periode }
\end{array}\right] \times\left[\begin{array}{c}
\text { biaya pemesanan } \\
\text { per pesanan }
\end{array}\right]=\left(\frac{R}{Q}\right) \cdot S
$$

Jadi : $\frac{Q}{2} \cdot C I=\frac{R}{Q} . \mathrm{S} \rightarrow Q C I=\frac{2 R S}{Q}$

$$
\mathrm{Q}^{2}=\frac{2 \mathrm{RS}}{\mathrm{CI}} \rightarrow \mathrm{Q}=\sqrt{\frac{2 \mathrm{RS}}{\mathrm{CI}}}
$$

dan jumlah biaya minimum $=\sqrt{2 \mathrm{RSCI}}$

$$
\mathrm{Q}=\mathrm{EOQ}=\sqrt{\frac{2 \mathrm{RS}}{\mathrm{CI}}}
$$

Keterangan:

$\mathrm{Q}=\mathrm{EOQ}=$ Jumlah pesanan ekonomis atau jumlah pesanan barang per pesanan agar jumlah biaya minimum

$\mathrm{R}=$ Jumlah permintaan setahun atau jumlah barang yang dibutuhkan dalam setahun

$\mathrm{S}=$ Biaya pemesanan per pesanan (ordering cost per order or set-up cost per run)

$\mathrm{C}=$ Biaya penyimpanan per satuan (unit) barang

$\mathrm{I}=$ Biaya penyimpanan (inventory carrying cost), dinyatakan dari nilai rata-rata pesanan

\section{b. Asumsi Economic Order Quantity (EOQ)}

Menurut Irham Fahmi (2016: 120) metode EOQ terdapat beberapa asumsi dan variabel yang terlihat jelas yaitu :

1) Total cost atau biaya total.

2) Ordering cost atau biaya pesanan.

3) Carrying cost atau biaya penyimpanan.

c. Persediaan Bahan Pengaman (Safety Stock) 
Menurut Gatot Nazir Ahmad (2018: 176) "Persediaan Pengaman (safety stock) adalah persediaan ekstra yang disismpan sebagai jaminan dalam menghadapi permintaan yang berfluktuasi”.

Faktor-faktor yang memperngaruhi besarnya safety stock ialah :

1) Sulit/tidaknya bahan/barang tersebut diperoleh

2) Kebiasaan pemasok menyerahkan barang/bahan

3) Besar/kecilnya jumlah barang/bahan yang dibeli setiap saat, dan

4) Sering/tidaknya mendapatkan pesanan mendadak Berikut merupakan rumus cara menghitung persediaan pengaman (safety stock) yang dapat dijelaskan dan diuraikan sebagai berikut :

kan sebagai berikut :

$$
\text { Safety stock }=\mathrm{z} \mathrm{x} \alpha
$$

\section{Keterangan:}

Safety stock $=$ persediaan pengaman .

$\mathrm{z}=$ standar normal deviasi (standar level).

$\alpha \quad=$ standar deviasi dari tingkat kebutuhan.

Rumus perhitungan standar deviasinya $(\alpha)$ adalah sebagai berikut dibawah ini:

$$
\alpha=\sqrt{\sum \frac{(X-\bar{X})^{2}}{n}}
$$

Keterangan :

$\alpha=$ standar deviasi dan tingkat kebutuhn

$\mathrm{x}=$ jumlah pemakaian bahan baku

$\mathrm{x}=$ Jumlah rata-rata pemakaian bahan baku.

$\mathrm{n}=$ Periode pemakaian bahan baku.

\section{d. Pemesanan Kembali (Reorder Point)}

Irham Fahmi (2016: 122) mengemukakan "reorder point adalah titik dimana suatu perusahaan atau institusi bisnis harus memesan barang atau bahan guna menciptakan kondisi persediaan yang terus terkendali".

Rumus perhitungan titik pemesanan kembali (reorder point)) sebagai berikut:

$$
R O P=(d . L)+\text { Safety Stock }
$$

Keterangan :

ROP=Titik pemesanan kembali.

$\mathrm{d}=$ Pemakaian bahan baku perhari (unit/hari).

$\mathrm{L}=$ Lead time atau waktu tunggu.

Safety stock $=$ Persediaan pengaman .

\section{e. Maksimum Persediaan (maximal Inventory)}

Formula cara melakukan perhitungan persediaan maksimum atau maximum inventory adalah dapat dijelaskan dan diuraikan sebagai berikut:

Maximum inventory $=$ safety stock $+E O Q$

Keterangan :

Maximum Investory = persediaan maksimum

Safety Stock = persediaan pengaman

$\mathrm{EOQ}=$ jumlah pesanan ekonomis (Economic Order Quantity)

\section{f. Total Biaya Persediaan Bahan Baku Atau Total Investory Cost (TIC)}

Rumus untuk jumlah biaya persediaan (total inventory cost) ialah sebagai berikut :

Dimana :

$$
T C=\frac{Q}{2} C I+\frac{R}{Q} S
$$

$\mathrm{TC}=$ jumlah biaya persediaan setahun

$\mathrm{R}=$ jumlah permintaan barang

$\mathrm{C}=$ biaya per unit barang (biaya bisa berarti harga, kalau barang harus dibeli)

$\mathrm{Q}=$ jumlah pesanan ekonomis, agar jumlah biaya minimum

$\mathrm{I}=$ biaya penyimpanan sebagai persentase dari rata-rata persediaan (carrying cost) merupakan persentase tertentu dari biaya atau harga per unit barang

$\mathrm{S}=$ biaya pemesanan per pesanan ( set up cost)

Total biaya persediaan bahan baku atau Total Investory Cost (TIC) merupakan total biaya yang dibutuhkan perusahaan untuk memenuhi persediaan bahan baku minimal dalam satu tahun.

\section{METODE PENELITIAN}

\section{A. Metode Penelitian}

Metode penelitian yang digunakan dalam penelitian ini adalah penelitian deskriptif dengan menggunakan pendekatan kuantitatif.

"Penelitian deskriptif merupakan penelitian yang dilakukan untuk mengetahui keberadaan variabel mandiri, baik hanya satu variabel atau lebih tanpa membuat perbandingan atau menghubungkan dengan variabel lain (variabel mandiri adalah variabel yang berdiri sendiri, bukan variabel independen karena jika independen selalu dipasangkan dengan variabel dependen)". 
Sedangkan "Penelitian kuantitatif dapat diartikan sebagai metode penelitian yang berlandasan pada filsafat positivisme, digunakan untuk meneliti pada populasi atau sampel tertentu, teknik pengambilan sampel pada umumnya dilakukan secara random, pengumpulan data menggunakan instrumen penelitian, analisis data bersifat kuantitatif/statistik" (Sugiyono, 2018: 35).

\section{B. Definisi Operasional Penelitian}

Definisi operasional variabel adalah pengertian variabel yang diungkapkan dalam definisi konsep tersebut, secara operasional, secara praktis,secara nyata dalam objek penelitian. Definisi operasional merupakan suatu penjelasan konsep yang terdapat pada judul penelitian yang diukur jenis dan tingkatnya sehingga variabel-variabel yang diteliti menjadi jelas.

Persediaaan adalah unsur yang paling aktif dalam operasi perusahaan, yang secara terus menerus diproduksi untuk memenuhi permintaan pelanggan.

Dalam penelitian ini variabel yang akan diteliti adalah satu variabel yaitu persediaan bahan baku.

\section{Metode Pengumpulan Data}

Metode pengumpulan data yang penulis gunakan dalam penelitian ini adalah sebagai berikut

\section{1) Interview / wawancara}

Wawancara dilalukan dengan pemilik usaha yang lebih mengetahui secara mendalam tentang apa yang diangkat dalam penelitian ini yaitu mengenai persediaan. Dari metode ini menghasilkan data tentang sejarah, struktur organisasi pada Usaha Sari Tahu Gunung Kancil Pringsewu.

\section{2) Observasi}

Dalam metode ini peneliti melakukan pengamatan langsung terhadap persediaan bahan baku yang terdapat di Usaha Sari Tahu Gunung Kancil Pringsewu. Seperti mengamati sistem pengadaan bahan baku, dan proses produksi.

\section{3) Dokumentasi}

Dokumentasi merupakan catatan peristiwa yang sudah berlalu. Dokumen bisa berbentuk tulisan, gambar, atau karya-karya monumental dari seseorang". Dengan metode ini diperoleh data tentang persediaan bahan baku pada Usaha Sari Tahu.

\section{Instrumen Penelitian}

Untuk mendapatkan data yang akurat tentang persediaan bahan baku yang di peroleh langsung dari sumbernya dengan menggunakan cara:

\section{Pedoman wawancara}

Dengan menggunakan pedoman wawancara peneliti memperoleh penjelasan dengan menggunakan tanya jawab dan menghasilkan data tentang sejarah,struktur organisasi, pada usaha Sari Tauhu Gunung Kancil Ptingsewu.

\section{Pedoman observasi}

Dengan menggunakan pedoman observasi peneliti melakukan pengamatan langsung terhadap persediaan bahan baku pada usaha Sari Tahu Gunung Kancil Pringsewu.

\section{Pedoman dokumentasi}

Dalam penelitian ini di ambil dari dokumen tentang persediaan bahan baku pada usaha Sari Tahu Gunung Kancil Pringsewu.

\section{E. Populasi dan Sampel}

Populasi merupakan wilayah generalisasi yang terdiri atas : obyek/subyek yang mempunyai kualitas dan karakteristik tertentu yang ditetapkan oleh peneliti untuk dipelajari dan kemudian ditarik kesimpulannya". Populasi dalam penelitian ini adalah data persediaan bahan baku yang terdapat pada produksi Sari Tahu Gunung Kancil Pringsewu selama 2 tahun yaitu tahun 2017 dan 2018.

Sedangkan "sampel adalah bagian dari jumlah dan karakteristik yang dimiliki oleh populasi tersebut" (Sugiyono, 2018: 149). Sampel dalam penelitian ini adalah data yang berhubungan dengan pembelian dan pemakaian bahan baku.

\section{E. Metode Analisis Data}

Untuk menghitung persediaan bahan bahan Peneliti menggunakan analisis penelitian sebagai berikut:

\section{Economic Order Quantity (EOQ)}

a. Dengan menggunakan pendekata tabel untuk mencapai Economic Order Quantity (EOQ) 
b. Dengan menggunakan pendekatan matematis, dengan rumus sebagai berikut:

\section{Keterangan:}

$$
\mathrm{Q}=\mathrm{EOQ}=\sqrt{\frac{2 \mathrm{RS}}{\mathrm{CI}}}
$$

$\mathrm{Q}=\mathrm{EOQ}=$ Jumlah pesanan ekonomis atau jumlah pesanan barang per pesanan agar jumlah biaya minimum.

$\mathrm{R}=$ Jumlah permintaan setahun atau jumlah barang yang dibutuhkan dalam setahun

$\mathrm{S}=$ Biaya pemesanan per pesanan (ordering cost per order or set-up cost per run)

$\mathrm{I}=$ Biaya penyimpanan (inventory carrying cost), dinyatakan dari nilai rata-rata pesanan

\section{Frekuensi pembelian}

Metode EOQ mengacu pada penentuan jumlah yang sama dalam setiap kali pembelian pembelian. Sehingga kegiatan pembelian dalam satu tahun dapat diketahui dengan rumus sebagai berikut :

Dimana : $I=\frac{D}{E O Q}$

I= frekuensi pemesanan dalam 1 tahun

$\mathrm{D}=$ jumlah kebutuhan bahan selama satu tahun

$\mathrm{EOQ}=$ jumlah pembelian bahan sekali pesan

\section{Persediaan Bahan Pengaman (Safety Stock)}

Rumus cara menghitung persediaan pengaman (safety stock) yang dapat dijelaskan dan diuraikan sebagai berikut :

\section{Safety stock $=\mathrm{z}$ x $\alpha$}

Dimana penjelasan tersebut sebagai berikut.

Safety stock= persediaan pengaman.

$\mathrm{z}=$ standar normal deviasi (standar level).

$\alpha=$ standar deviasi dari tingkat kebutuhan.

Rumus perhitungan standar deviasinya $(\alpha)$ adalah sebagai berikut dibawah ini:

Dimana penjelasan tersebut adalah antara lain sebagai berikut :

$\alpha=$ standar deviasi dari tingkat kebutuhan.

$\mathrm{x}=$ jumlah pemakaian bahan baku.

$\bar{x}=$ jumlah rata-rata pemakaian bahan baku.

$\mathrm{n}=$ periode pemakaian bahan baku

\section{Pemesanan Kembali (Reorder Point)}

Formula cara melakukan perhitungan titik pemesanan kembali atau reorder point (ROP) dapat dijelaskan dan diuraikan sebagai berikut:

$$
R O P=(d \cdot L)+\text { Safety Stock }
$$

Dimana penjelasan tersebut adalah antara lain sebagai berikut :

$\mathrm{ROP}=$ titik pemesanan kembali.

$\mathrm{d}=$ pemakaian bahan baku perhari (unit/hari).

$\mathrm{L}=$ lead time atau waktu tunggu.

Safety stock= persediaan pengaman.

\section{Persediaan Maksimum (Maximum Inventory)}

Dibawah ini merupakan formula cara melakukan perhitungan persediaan maksimum atau maximum inventory adalah dapat dijelaskan dan diuraikan sebagai berikut:

\section{Maximum Inventory $=S S+E O Q$}

Keterangan :

Maximum Investory= persediaan maksimum

$\mathrm{SS}=$ safety stock

$\mathrm{EOQ}=$ jumlah pesananekonomis(Economic

Order Quantity)

\section{Total Biaya Persediaan Bahan Baku Atau \\ Total Investory Cost (TIC)}

Rumus untuk jumlah biaya persediaan (total inventory cost) ialah sebagai berikut :

$$
T C=\frac{Q}{2} C I+\frac{R}{Q} S
$$

\section{Dimana:}

$\mathrm{TC}=$ jumlah biaya persediaan setahun

$\mathrm{R}=$ jumlah permintaan barang

$\mathrm{C}=$ biaya per unit barang (biaya bisa berarti harga,kalau barang harus dibeli)

$\mathrm{Q}=$ jumlah pesanan ekonomis, agar jumlah biaya minimum

I = biaya penyimpanan sebagai biaya persentase dari rata-rata persediaan (caryung cost)merupakan persentase tertentu dari biaya atau harga per unit barang.

$\mathrm{S}$ = biaya pemesanan per pesanan (setupcost)

IV. HASIL PENELITIAN DAN PEMBAHASAN

A. Pengumpulan dan Penyajian Data 


\section{a. Pembelian Dan Pemakaian Bahan Baku}

Pada penelitian ini, pengumpulan data dilakukan dengan melihat dokumentasi yang terdapat di Sari Tahu Gunung Kancil Pringsewu. Untuk kuantitas pemesanan bahan baku yang optimal dalam menyediakan bahan baku untuk proses produksi Tahu terlebih dahulu harus mengetahui jumlah kebutuhan setiap tahunnya. Berikut data pembelian dan pemakain bahan baku yang diproleh dari Sari Tahu Gunung Kancil Pringsewu:

Tabel 2

Pembelian dan pemakaian Bahan Baku Kedelai Tahun 2017 dan 2018

(dalam satuan $\mathrm{kg}$ )

\begin{tabular}{|l|l|c|c|c|c|}
\hline \multirow{2}{*}{ No } & \multirow{2}{*}{ Bulan } & \multicolumn{2}{|c|}{ Tahun 2017} & \multicolumn{2}{c|}{ Tahun 2018} \\
\cline { 2 - 5 } 1. & Januari & Pembelian & Pemakaian & Pembelian & Pemakaian \\
\cline { 2 - 5 } 2. & Febuari & 2500 & 2295 & 2700 & 2570 \\
\cline { 2 - 5 } 3. & Maret & 2500 & 2040 & 2500 & 2400 \\
\cline { 2 - 5 } 4. & April & 2500 & 2430 & 2500 & 2430 \\
\cline { 2 - 5 } 5. & Mei & 3000 & 2540 & 2500 & 2340 \\
\cline { 2 - 5 } 6. & Juni & 3000 & 2600 & 3000 & 2700 \\
\cline { 2 - 5 } 7. & Juli & 3000 & 2800 & 4500 & 2800 \\
\cline { 2 - 5 } 8. & Agustus & 4500 & 4050 & 3000 & 2700 \\
\cline { 2 - 5 } 9. & Septembr & 2500 & 2080 & 2500 & 2080 \\
\cline { 2 - 5 } 10. & Oktober & 2500 & 2360 & 2500 & 2460 \\
\cline { 2 - 5 } 11. Novembr & 2000 & 1950 & 2500 & 2210 \\
\hline 12. Desember & 2500 & 2025 & 2500 & 2295 \\
\hline Jumlah & 33000 & 29535 & 33700 & 31035 \\
\hline Rata - rata & 2750 & 2461,25 & 2808,33 & 2586,25 \\
\hline
\end{tabular}

Dari tabel 2 menunjukan bahwa bahwa Usaha Sari Tahu Gunung Kancil Pringsewu melakukan pembelian bahan baku berdasarkan dengan perhitungan kebutuhan produksi serta persediaan bahan baku yang terdapat digudang. Sari Tahu Pringsewu melakukan pembelian setiap 15 hari sekali atau 24 kali dalam setahun, dengan alasan sebagai persediaan dalam proses produksi dan untuk mengantisipasi adanya kenaikan harga bahan baku serta keterlambatan dalam pengiriman. Pada tahun 2017 dan 2018 Usaha Sari Tahu Gunung Kancil Pringsewu menunjukan pemakaian bahan baku setiap tahun mengalami naik turun.

\section{Biaya Pemesanan}

Sari Tahu Gunung Kancil Pringsewu mengeluarkan biaya pemesanan dalam melakukan pemesanan untuk memproduksi Tahu. Biaya pemesanan bahan baku meliputi biaya telepon, biaya pengiriman dan biaya bongkar barang. Besarnya biaya pemesanan dapat dilihat pada tabel berikut ini:
Tabel 3

Biaya pemesanan Bahan Baku Tahun 2017 dan 2018 (dalam satuan Rp)

\begin{tabular}{|c|c|c|c|}
\hline \multirow{2}{*}{ Bahan } & \multirow{2}{*}{ Jenis Biaya } & \multicolumn{2}{|c|}{ Per Pesanan } \\
& & 2017 & 2018 \\
\hline \multirow{4}{*}{ Kedelai } & Biaya Telepon & 7.000 & 10.000 \\
& Biaya Pengiriman & 25.000 & 25.000 \\
& Biaya Bongkar Barang & 10.000 & 15.000 \\
& Jumlah & $\mathbf{4 7 . 0 0 0}$ & $\mathbf{5 0 . 0 0 0}$
\end{tabular}

Sumber : Data biaya pemesanan Usaha Sari

Tahu Gunung Kancil Pringsewu tahun 2018

Terlihat dari tabel 3 bahwa biaya pengiriman dari tahun 2017 dan 2018 terus mengalami kenaikan. Serta besarnya biaya pemesanan untuk bahan baku kedelai.

\section{Biaya Penyimpanan}

Biaya penyimpanan yang dibutuhkan untuk analisis lebih lanjut, diperhitungkan dalam bentuk persentase yaitu persentase dari nilai persediaan. Sari Tahu Gunung Kancil Pringsewu menetapkan estimasi untuk biaya penyimpanan persediaan bahan baku sebesar $10 \%$ dari nilai persediaan. Adapun tabel persediaan bahan baku pada produksi Tahu Sari Tahu Gunung Kancil Pringsewu sebagai berikut:

Tabel 4

Presentase Biaya Simpan, Harga Per kg, dan Biaya Penyimpanan

\begin{tabular}{|c|c|c|c|c|}
\hline $\begin{array}{c}\text { Bahan } \\
\text { baku }\end{array}$ & Tahun & $\begin{array}{c}\text { \% Biaya } \\
\text { Simpanan }\end{array}$ & $\begin{array}{c}\text { Harga } \\
(\mathrm{Rp}) \\
\text { Per kg }\end{array}$ & $\begin{array}{c}\text { Biaya } \\
\text { Penyimpanan }\end{array}$ \\
Kedelai & 2017 & $10 \%$ & 6.500 & 650 \\
& 2018 & $10 \%$ & 7.000 & 700 \\
\hline
\end{tabular}

Sumber: dari usaha sari tahu yang telah diolah.

\section{Analisis Data}

Pembeliaan bahan baku yang dilakukan Usaha Sari Tahu Gunung Kancil Pringsewu menggunakan kebijakan perusahaan, kebijakan tersebut tidak memperhitungkan pembelian yang optimal yaitu bertujuan supaya produksi berjalan cepat. Pada periode 2017 dan 2018 Sari Tahu Gunung Kancil Pringsewu melakukan pembelian sebanyak 24 kali dalam setahun. Berdasarkan data-data yang telah disebutkan sebelumnya,maka jumlah pesanan yang ekonomis dapat ditentukan sebagai berikut:

\section{Kuantitas Pembelian bahan baku kedelai optimal tahun 2017,}




\section{a. Econimic Order Quantity (EOQ),}

Untuk mencapai EOQ (Economic Order Quantity) dapat juga menggunakan pendekatan matematis, sebagai berikut:

$$
\begin{aligned}
& \mathrm{Q}=\mathrm{EOQ}=\sqrt{\frac{2 \mathrm{RS}}{\mathrm{CI}}} \\
& Q=E O Q=\sqrt{\frac{2(29.535)(47.000)}{(6500)(0,10)}} \\
& =\sqrt{4.271 .216}
\end{aligned}
$$

Frekuensi Pembelian : $\mathrm{r}=$

$$
\begin{aligned}
& =\frac{29.535}{2.066,69} \\
& =14,290 \text { atau } 14 \mathrm{kali} \text { (dibulatkan) }
\end{aligned}
$$

Berdasarkan pendekatan EOQ didapat jumlah pesanan yang ekonomis sebesar 2.066,69 kg dengan 14 kali pemesanan. Biaya minimum dicapai pada saat biaya penyimpanan (carrying cost) sama dengan biaya pemesanan

(ordering cost), yaitu biaya penyimpanan (carrying cost) atau C = 10\% (1.033,346) (6500) sebesar Rp.671.675 dan biaya pemesanan (ordering cost) atau $\mathrm{S}=14,290968 \times 47.000$ sebesar Rp.671.675 Dengan jumlah biaya minimum yaitu biaya penyimpanan (carrying cost) + biaya pemesanan (ordering cost) sebesar Rp.671.675+ Rp.671.675 = Rp. 1.343 .350

\section{b. Persediaan Pengaman (Safety Stock)}

Persediaan pengaman (Safety Stock) berfungsi untuk melindungi perusahaan dari risiko kehabisan bahan baku (Stock Out) dan keterlambatan penerimaan bahan baku yang dipesan. Usaha Sari Tahu Gunung Kancil Pringsewu menggunakan standar deviasi (standar penyimpangan 5\%) (z) nilai 1,65 .

Untuk menentukan jumlah persediaan pengaman (Safety Stock) terlebih dahulu harus mencari standar deviasi, sebagai berikut:

$$
\begin{aligned}
a & =\sqrt{\sum\left(\frac{x-\bar{x}}{n}\right)^{2}}=\sqrt{\frac{3.496 .139,27}{12}} \\
& =\sqrt{291.344,93917}=539,76 \mathrm{~kg}
\end{aligned}
$$

Untuk menentukan persediaan pengaman (Safety Stock) sebagai berikut: SS = Zx $\alpha$

$\mathrm{SS}=16,5 \times 539,76=890,6 \mathrm{~kg}$

Jadi persediaan pengaman (Safety Stock) yang harus ada untuk persediaan bahan baku kedelai tahun 2017 pada Usaha Sari Tahu Gunung Kancil Pringsewu adalah 890,6 kg.

\section{c. Pemesanan Kembali (Reorder Point)}

Titik pemesanan kembali (Reorder Point) diperlukan agar pembelian bahan baku dengan metode EOQ (Economic Order Quantity) tidak menganggu kelancaran proses produksi, karena jika terdapat kesalahan dalam melakukan pemesanan barang maka akan mengakibatkan penimbunan persediaan maupun habisnya persediaan. Yang dimaksud dengan lead time dalam penelitian ini adalah tenggang waktu yang diperlukan antara saat pemesanan bahan baku dilakukan dengan datangnya bahan baku yang dipesan.

Sebelum menentukan ROP (Reorder Point), terlebih dahulu mencari berapa banyak pemakaian bahan baku per hari (d) jika jumlah hari kerja pertahun

$$
\text { (t) } 300 \text { hari, adalah: } \begin{aligned}
\mathrm{d}=\frac{D}{t} & =\frac{29.535}{300} \\
& =98,45 \mathrm{~kg} / \text { hari }
\end{aligned}
$$

Jadi untuk menentukan Titik Pemesanan Kembali (Reorder Point) yaitu sebagai berikut:

$$
\begin{aligned}
R O P & =(d \times L)+\text { Safety Stock } \\
& =(98,45 \times 2)+890,6 \\
& =1.087,5 \mathrm{~kg}
\end{aligned}
$$

Usaha Sari Tahu Gunung Kancil Pringsewu pada tahun 2017 harus melakukan pemesanan kembali pada saat persediaan bahan baku kedelai sebesar $1.087,5 \mathrm{~kg}$.

\section{d. Persediaan Maksimum (Maximum Inventory)}

Persediaan maksimum (Maximum Inventory) diperlukan oleh Sari Tahu Gunung Kancil Pringsewu agar jumlah persediaan yang ada digudang tidak berlebihan sehingga tidak terjadi pemborosan modal kerja. Adapun untuk mengetahui besarnya persediaan maksimum (Maximum Inventory) dapat menggunakan rumus sebagai berikut :

Maximum Inventory $=$ Safety Stock $+E O Q$ $M I=890,6 \mathrm{~kg} \times 2.066,69=2,957,29 \mathrm{~kg}$

Jadi jumalah persediaan maksimum (Maximum Inventory) bahan baku kedelai pada tahun 2017 adalah sebesar $2.957,29 \mathrm{~kg}$.

\section{e. Total Biaya Persediaan Bahan Baku Atau Total Investory Cost (TIC)}


Perhitungan biaya total persediaan bahan baku (Total Investory Cost) digunakan untuk membuktikan bahwa dengan adanya jumlah pembelian bahan baku yang optimal dengna metode EOQ (Economic Order Quantity) akan dicapai biaya total persediaan bahan baku yang optimal pula. Sehingga Usaha Sari Tahu dapat mengefisiensi total biaya persediaan (Total Investory Cost) yang dikeluarkan perusahaan. Perhitungan total biaya persediaan menurut metode EOQ (Economic Order Quantity) dengan rumus Total Investory Cost (TIC) dalam rupiah sebagai berikut:

$$
\begin{gathered}
T C=\frac{Q}{2} C I+\frac{R}{Q} S \\
=\frac{2.066,69}{2} 6500 \cdot 10 \%+\frac{29.535}{2.066,69} 47.000 \\
=671.674,25+671.675,5 \\
=1.343 .349,75
\end{gathered}
$$

Sehingga total biaya persediaan yang dikeluarkan perusahaan menurut metode EOQ (Economic Order Quantity) untuk bahan baku kedelai tahun 2017 adalah sebesar Rp. 1.343.348,75

\section{Kuantitas pembelian bahan baku kedelai optimal tahun 2018}

\section{a. Economic Order Quantity (EOQ)}

untuk mencapai EOQ (Economic Order Quantity) dapat juga menggunakan pendekatan matematis, sebagai berikut:

$$
\begin{aligned}
Q & =E O Q=\sqrt{\frac{2 \mathrm{RS}}{\mathrm{CI}}} \\
Q=E O Q & =\sqrt{\frac{2(31.035)(50.000)}{(7000)(0,10)}} \\
= & \sqrt{\frac{3.103 .500 .000}{700}} \\
& =\sqrt{4.433 .571,4286} \\
& =14,7392 \text { atau } 15 \mathrm{kali} \text { (dibulatkan) } \\
& =2.105,60 \mathrm{~kg}
\end{aligned}
$$

Berdasarkan pendekatan EOQ didapat jumlah pesanan yang ekonomis sebesar 2.105,60 kg dengan 15 kali pemesanan. Biaya minimum dicapai pada saat biaya penyimpanan (carrying cost) sama dengan biaya pemesanan (ordering cost), yaitu biaya penyimpanan (carrying cost) atau C $=10 \%(1.052,8)(7000)$ sebesar Rp.736.960 dan biaya pemesanan (ordering cost) atau $S=14,7392 \times 50000$ sebesar Rp.736.960. Dengan jumlah biaya minimum yaitu biaya penyimpanan (carrying cost) + biaya pemesanan (ordering cost) sebesar Rp.736.960+ Rp.736.960 = Rp. 1.473 .920

\section{b. Persediaan Pengaman (Safety Stock)}

Persediaan pengaman (Safety Stock) berfungsi untuk melindungi perusahaan dari risiko kehabisan bahan baku (Stock Out) dan keterlambatan penerimaan bahan baku yang dipesan. Pada tingkat persediaan dapat ditekan seminimal mungkin, sehingga Usaha Sari Tahu Gunung Kancil Pringsewu melakukan perhitungan untuk menentukan safety stock yang paling optinal untuk menentukan besarnya pengamanan yang digunakan analisis statistik. Usaha Sari Tahu Gunung Kancil Pringsewu menggunakan standar deviasi (standar penyimpangan $5 \%$ ) (z) nilai 1,65.

Untuk menentukan jumlah persediaan pengaman (Safety Stock) terlebih dahulu harus mencari standar deviasi, sebagai berikut:

$$
\begin{aligned}
a & =\sqrt{\sum\left(\frac{x-\bar{x}}{n}\right)^{2}}=\sqrt{\frac{2.842 .656,25}{12}} \\
& =\sqrt{236.888,02083}=486,7114 \mathrm{~kg}
\end{aligned}
$$

Untuk menentukan persediaan pengaman (Safety Stock) sebagai berikut:

$$
\begin{aligned}
& S S=z \times a \\
& S s=16,5 \times 486,7114=803,07 \mathrm{Kg}
\end{aligned}
$$

Sehingga persediaan pengaman (Safety Stock) yang harus ada untuk persediaan bahan kedelai tahun 2018 pada Usaha Sari Tahu Gunung Kancil Pringsewu adalah 803,7 kg.

\section{c. Pemesanan Kembali (Reorder Point)}

Titik pemesanan kembali (Reorder Point) diperlukan agar pembelian bahan baku dengan metode EOQ (Economic Order Quantity) tidak menganggu kelancaran proses produksi, karena jika terdapat kesalahan dalam melakukan pemesanan barang maka akan mengakibatkan penimbunan 
persediaan maupun habisnya persediaan. Yang dimaksud dengan lead time dalam penelitian ini adalah tenggang waktu yang diperlukan antara saat pemesanan bahan baku dilakukan dengan datangnya bahan baku yang dipesan.

Sebelum menentukan ROP (Reorder Point), terlebih dahulu mencari berapa banyak pemakaian bahan baku per hari (d) jika jumlah hari kerja pertahun

$$
\begin{aligned}
& \text { (t) } 300 \text { hari, adalah: } \mathrm{d}=\frac{D}{t} \\
& =\frac{31.035}{300}=103,45 \mathrm{~kg} / \text { hari }
\end{aligned}
$$

Jadi untuk menentukan Titik Pemesanan Kembali (Reorder Point) yaitu sebagai berikut:

$$
\begin{aligned}
\text { ROP } & =(d \times L)+\text { Safety Stock } \\
& =(103,45 \times 2)+803,07 \\
& =1.009,97 \mathrm{~kg}
\end{aligned}
$$

Usaha Sari Tahu Gunung Kancil Pringsewu pada tahun 2018 harus melakukan pemesanan kembali pada saat persediaan bahan baku kedelai sebesar $1.009,97 \mathrm{~kg}$.

\section{d. Persediaan Maksimum (Maximum Inventory)}

Persediaan maksimum (Maximum Inventory) diperlukan oleh Sari Tahu Gunung Kancil Pringsewu agar jumlah persediaan yang ada digudang tidak berlebihan sehingga tidak terjadi pemborosan modal kerja. Adapun untuk mengetahui besarnya persediaan maksimum (Maximum Inventory) dapat menggunakan rumus sebagai berikut :

$$
\begin{aligned}
\text { Maximum Inventory } & =\text { Safety Stock }+E O Q \\
& =803,07+2.105,60 \\
& =2.908,67 \mathbf{~} \mathbf{g}
\end{aligned}
$$

Jadi jumalah persediaan maksimum (Maximum Inventory) bahan baku kedelai pada tahun 2018 adalah sebesar $2.908,67 \mathrm{~kg}$.

\section{e. Total Biaya Persediaan Bahan Baku Atau Total Investory Cost (TIC)}

Perhitungan biaya total persediaan bahan baku (Total Investory Cost) digunakan untuk membuktikan bahwa dengan adanya jumlah pembelian bahan baku yang optimal dengna metode
EOQ (Economic Order Quantity) akan dicapai biaya total persediaan bahan baku yang optimal pula. Sehingga Usaha Sari Tahu dapat mengefisiensi total biaya persediaan (Total Investory Cost) yang dikeluarkan perusahaan. Perhitungan total biaya persediaan menurut metode EOQ (Economic Order Quantity) dengan rumus Total Investory Cost (TIC) dalam rupiah sebagai berikut:

$$
\begin{aligned}
& T C=\frac{Q}{2} C I+\frac{R}{Q} S \\
& =\frac{2.105,60}{2} 7000 \cdot 10 \%+\frac{31.035}{2.105,60} 50.000 \\
& =736.960+736.963,3=1.473 .923,3
\end{aligned}
$$

Sehingga total biaya persediaan yang dikeluarkan perusahaan menurut metode EOQ (Economic Order Quantity) untuk bahan baku kedelai tahun 2017 adalah sebesar Rp. 1.473.923,3 sedangkan untuk perhitungan total biaya persediaan menggunakan kebijakan perusahaan akan dihitung menggunakan persediaan rata-rata yang ada diperusahaan dengan menggunakan rumus sebagai berikut:

$T I C=($ Persediaan Rata - rata $)(C)+(P)(F)$

Dimana :

$\mathrm{C}=$ biaya penyimpanan

$\mathrm{P}=$ biaya pemesanan tiap kali pesan

$\mathrm{F}=$ frekuensi pembelian yang dilakukan perusahaan

Sedangkan persediaan rata-rata bahan baku perusahaan adalah sebagai berikut:

Tabel 5

Persediaan Rata-Rata Bahan Baku Tahun 2017 dan 2018

\begin{tabular}{|c|c|c|c|l|}
\hline $\begin{array}{c}\text { Bahan } \\
\text { Baku }\end{array}$ & Tahun & $\begin{array}{c}\text { Pembelian } \\
\text { Kedelai }\end{array}$ & $\begin{array}{c}\text { Frekunsi } \\
\text { Pembelian }\end{array}$ & $\begin{array}{c}\text { Persediaan } \\
\text { Rata-Rata }\end{array}$ \\
\hline \multirow{2}{*}{ Kedelai } & 2017 & 33.000 & 24 & 1.375 \\
\cline { 2 - 5 } & 2018 & 33.700 & 24 & $1.404,17$ \\
\hline
\end{tabular}

Sehingga TIC menggunakan kebijakan perusahaan sebagai berikut :

1. TIC bahan baku kedelai tahun 2017

$$
T I C=(1.375)(650)+(47.000)(24)
$$




$$
\begin{aligned}
& T I C=893.750+1.128 .000 \\
& T I C=2.021 .750
\end{aligned}
$$

2. TIC bahan baku kedelai tahun 2018

$$
\begin{gathered}
T I C=(1.404,17)(700)+(50.000)(24) \\
T I C=982.919+1.200 .000 \\
T I C=2.182 .919
\end{gathered}
$$

\section{Pembahasan Hasil Penelitian}

Dari data yang diperoleh dari Sari Tahu Gunung Kancil Pringsewu menunjukan bahwa hubungan antara Economic Order Quantity (EOQ), Safety Stock, Reorder Point (ROP) dan Maximum Inventory bahan baku kedelai selama periode tahun 2017 dan 2018 adalah sebagai berikut:

Tabel 6

Gambaran Persediaan Kedelai Antara Kebijakan Perusahaan dengan

Metode Economic Order Quantity (EOQ) Tahun 2017 dan 2018

(dalam kg)

\begin{tabular}{|l|c|c|c|c|c|c|}
\hline \multirow{2}{*}{ Keterangan } & \multicolumn{2}{|c|}{$\begin{array}{c}\text { Kebijakan } \\
\text { Perusahaan }\end{array}$} & \multicolumn{2}{c|}{$\begin{array}{c}\text { Metode } \\
\text { Economic Order } \\
\text { Quantity (EOQ) }\end{array}$} & \multicolumn{2}{|c|}{ Selisih Efisien } \\
\cline { 2 - 7 } & 2017 & 2018 & 2017 & 2018 & 2017 & 2018 \\
\hline $\begin{array}{l}\text { Kuantitas } \\
\text { Pembelian }\end{array}$ & 1375 & 1404,17 & 2066,69 & 2105,60 & 691,69 & 701,43 \\
\hline $\begin{array}{l}\text { Frekuensi } \\
\text { Pembelian }\end{array}$ & 24 & 24 & 14 & 15 & 10 & 9 \\
\hline SafetyStock & - & - & 890,6 & 803,07 & 890,6 & 803,07 \\
\hline $\begin{array}{l}\text { Reorder } \\
\text { Point }\end{array}$ & - & - & 1087,5 & 1009,97 & 1087,5 & 1009,97 \\
\hline $\begin{array}{l}\text { Maximum } \\
\text { Inventory }\end{array}$ & - & - & 2957,29 & 2908,67 & 2957,29 & 2908,67 \\
\hline
\end{tabular}

\section{Bahan Baku kedelai Tahun 2017}

Untuk melakukan pembelian bahan baku yang ekonomis maka usaha sari tahu harus melakukan pembelian bahan baku kedelai dengan jumlah sebesar ${ }^{2.066,69} \mathrm{~kg}$ sebanyak 14 kali dan pada saat persediaan pengaman (Safety Stock) digudang sebesar $890,6 \mathrm{~kg}$. Dengan demikian saat pemesanan bahan baku diterima dengan waktu tunggu (lead time) 2 hari, maka usaha ini melakukan pembelian ulang (Reorder Point) saat persediaan yang tersisa sebesar $1.087,5 \mathrm{~kg}$ sedangkan untuk menghindari jumlah persediaan bahan baku yang terlalu besar (over stock) maka persediaan maksimum (Maximum Inventory) yaitu sebesar $2.957,29 \mathrm{~kg}$.

\section{Bahan Baku kedelai 2018}

Untuk melakukan pembelian bahan baku yang ekonomis maka Usaha Sari Tahu harus melakukan pembelian bahan baku kedelai dengan jumlah sebesar $2.105,60 \mathrm{~kg}$ sebanyak 15 kali dan pada saat persediaan pengaman (Safety Stock) digudang sebesar 803,07 kg. Dengan demikian saat pemesanan bahan baku diterima dengan waktu tunggu (lead time) 2 hari,maka Usaha ini melakukan pembelian ulang (Reorder Point) saat persediaan yang tersisa sebesar $1.009,9 \mathrm{~kg}$ sedangkan untuk menghindari jumlah persediaan bahan baku yang terlalu besar (over stock) maka persediaan maksimum (Maximum Inventory) yaitu sebesar $2.908,67 \mathrm{~kg}$.

Sedangkan untuk mengetahui perbandingan total biaya persediaan bahan baku menggunakan kebijakan perusahaan atau belum menggunakan manajemen persediaan bahan baku dengan menggunakan metode Economic Order Quantity (EOQ) serta penghematan biaya yang dapat diperoleh selama tahun 2017 dan 2018 adalah sebagai berikut :

\section{Tabel 7}

\section{Gambaran Antara Total Investory Cost (TIC) Menggunakan Kebijakan}

Perusahaan dengan Menggunakan Metode Economic Order Quantity (EOQ)

Pada Usaha Sari Tahu Gunung Kancil Pringsewu Tahun 2017 dan 2018 (dalam rupiah)

\begin{tabular}{|c|c|c|c|c|c|}
\hline \multirow{2}{*}{ Keterangan } & Tahun & $\begin{array}{c}\text { Metode } \\
\text { konvensional }\end{array}$ & Metode EOQ & $\begin{array}{c}\text { Selisish } \\
\text { biaya }\end{array}$ & $\begin{array}{c}\text { Efisiensi } \\
\text { biaya } \\
\text { persediaan }\end{array}$ \\
\hline \multirow{2}{*}{ Kedelai } & 2017 & 2.021 .750 & $1.343 .349,75$ & $678.400,25$ & $33 \%$ \\
\cline { 2 - 7 } & 2018 & 2.182 .919 & $1.473 .923,3$ & $708.995,7$ & $32 \%$ \\
\hline
\end{tabular}

\section{KESIMPULAN DAN SARAN}

\section{A. Kesimpulan}

Berdasarkan hasil penelitian dapat disimpulkan bahwa perencanaan persediaan bahan baku dengan menggunakan metode Economic Order Quantity (EOQ) lebih optimal dan efisien dari pada dengan kebijakan perusahaan atau sebelum menerapkan manajemen persediaan bahan baku, sehingga dapat menghemat Total Inventory Cost (TIC). 


\section{B. Saran}

a. Sbaiknya Sari Tahu Gunung Kancil Pringsewu menggunakan metode EOQ (Economic Order Quantity)

b. Usaha Sari Tahu Gunung Kancil Pringsewu agar memperhitungkan besarnya persediaan pengaman (Safety Stock), kapan dilakukan pemesanan kembali (Reorder Point), besarnya persediaan maksimum(Maximum Inventory), untuk meminimalisir terjadinya resiko persediaan bahan baku yang terlalu besar (over stock) ataupun persediaan bahan baku yang terlalu kecil (out of stock) karena akan mempengaruhi tingkat pendapatan, proses produksi, serta dapat meminimalkan biaya bahan baku.

\section{DAFTAR PUSTAKA}

Ahmad, Gatot Nazir. (2018). Manajemen Operasi. Jakaeta: Bumi Aksara

Fahmi, Irham. (2016). Manajemen Produksi dan Operasi. Bandung: Alfabeta.

Heizer, Jay dan Barry Render. (2016). Manajemen Operasi. Jakarta: Selemba Empat.

Prastiti, Ayu Esa Dwi. (2016) Analisis Penentuan $\underline{\text { Harga Pokoko Produksi Dengan }}$

Metode Activity Based Costing (Studi Kasus Pada CV. Indah Cemerlang

Setiawati,AnantasiaDianaLilis.(2017). Akuntansi Keuangan Menengah. Yogyakarta: Selemba Empat.

Simba, Mutiara. (2014). $\quad \underline{\text { Analisis }}$ Pengendalian Persediaan Bahan Baku Kayu Cempaka Pada Industri Mebel Dengan Menggunakan Metode EOQ (Studi Kasus Pada UD. Batu Zaman). Manado: Jurnal Ilmiah.

Supranto, Johannes. (2013). Riset Operasi untuk Pengambilan Keputusan. Jakarta: Raja Grafindo Persada.

Sri, Suharti. (2018). Kajian Perencanaan Persediaan Yang Optimal Dengan
Metode EOQ PadabPT. XYZ. Krawang: IndustryExplore. Vol. 3,No. 01 .

Sugiyono. (2018). Metode Penelitian Manajemen. Bandung: Alfabeta. 